\title{
European Society of Gastrointestinal Endoscopy (ESGE) Guidelines: flexible enteroscopy for diagnosis and treatment of small-bowel diseases
}

J. Pohl', M. Delvaux ${ }^{2}$, C. Ell' ${ }^{1}$, G. Gay ${ }^{2}$, A. May' ${ }^{1}$, C. J. J.Mulder ${ }^{3}$, M. Pennazio ${ }^{4}$, E. Perez-Cuadrado ${ }^{5}$, P. Vilmann ${ }^{6}$ and the ESGE Clinical Guidelines Committee

Institutions are listed at the end of article

\section{Introduction}

Until recently, large parts of the small bowel were not accessible with nonsurgical endoscopic techniques. In this scenario, the advent of video capsule endoscopy and balloon-assisted enteroscopy represented a major breakthrough. Although capsule endoscopy is a safe method that may provide imaging of the entire small bowel, major drawbacks are that biopsy sampling and endoscopic treatment cannot be performed; moreover, in many cases interpretation of nonspecific findings remains a concern.

In contrast to capsule endoscopy, flexible enteroscopy with push enteroscopy or balloon-assisted enteroscopy is labour-intensive and more invasive but allows real-time-controlled observation with the option for tissue sampling and endoscopic treatment. Push enteroscopy was established during the $1980 \mathrm{~s}$ but due to excessive loop formation it allows only limited visualization of the small intestine. This limitation has been overcome by the invention of balloonassisted enteroscopy, which may permit imaging of the entire small bowel by threading it onto the overtube, thereby minimizing looping and maximizing insertion. Initially, a double balloon enteroscopy (DBE) system was developed by Yamamoto and colleagues in 2001 [1]. This system has rapidly gained an established role in small-bowel investigation and therapy and is widely applied in clinical practice. Importantly, besides small-bowel endoscopy the DBE technique can be applied for additional indications, for example difficult colonoscopies, for gaining access to the pancreatic and biliary tract in patients with a surgically modified gastrointestinal tract, and access to the stomach in patients after bariatric surgery. Very recently, another balloon-assisted enteroscopy device with only one balloon at the tip of the overtube was introduced as the single balloon enteroscopy (SBE) system.

The present report constitutes a guide to the clinical application of flexible enteroscopy systems (push enteroscopy, DBE, and SBE) in the small bowel, based on published findings as well as personal experience of the authors ( Table 1 ). Recommendations concerning DBE are partially derived from a consensus that was developed during the 2nd International Conference on DBE in Berlin, 14 - 15 June 2007.

\section{Methods and equipment \\ $\nabla$}

\section{Push enteroscopy}

Push video enteroscopes are 200-250-cm long (dependent on type and manufacturer), and might be used with a stiff overtube $(100-120 \mathrm{~cm})$ to prevent looping of the enteroscope in the stomach. Although initial studies have shown an increase in the depth of insertion with the use of an overtube [2,3], later studies with graded stiffness enteroscopes have questioned the additional value of the overtube [4,5]. Therefore many units no longer use it in routine practice. Push enteroscopy for the lower digestive tract is not commonly performed, because insertion depth of colonoscopy with ileoscopy appears to be equivalent to lower push enteroscopy [6].
Bibliography

DOI $10.1055 / \mathrm{s}-2008-1077371$

Endoscopy 2008; 40:

609-618 ๑ Georg Thieme Verlag KG

Stuttgart · New York

ISSN 0935-8943

Corresponding author

J. Pohl, MD, PhD

Internal Medicine II

Dr Horst Schmidt Klink Wiesbaden

65199 Wiesbaden

Germany

Fax: +49-611-432418

pohljuergen@web.de

- Push enteroscopes are long devices without balloon assistance. Looping of the enteroscope in the stomach and intestine is a major problem during insertion. 
The DBE system consists of an endoscope with a working length of $200 \mathrm{~cm}$ and a flexible overtube. Latex balloons are attached at both the tip of the enteroscope and the overtube. The insertion technique is based on alternating "push-and-pull" maneuvers.
The SBE system consists of an endoscope with a working length of $200 \mathrm{~cm}$ and a flexible overtube. A latex-free balloon is attached at the tip of the overtube but not on the endoscope.
Table 1 Summary of ESGE guidelines for flexible endoscopy including category of evidence and grading of recommendations (see Table 2)

\begin{tabular}{|c|c|c|}
\hline ESGE guidelines for flexible enteroscopy & Category of evidence & $\begin{array}{l}\text { Grading of } \\
\text { recommendation }\end{array}$ \\
\hline $\begin{array}{l}\text { Diagnostic efficacy of DBE for mid-gastrointestinal } \\
\text { bleeding is superior to push enteroscopy }[37,38]\end{array}$ & $1 \mathrm{~b}$ & A \\
\hline $\begin{array}{l}\text { Diagnostic efficacy of DBE for mid-gastrointestinal } \\
\text { bleeding is similar to video capsule endoscopy } \\
{[42-44]}\end{array}$ & $1 b$ & A \\
\hline $\begin{array}{l}\text { Patients with bleeding sites identified on capsule } \\
\text { endoscopy should subsequently undergo flexible } \\
\text { enteroscopy for endoscopic treatment }[1,7,15-22]\end{array}$ & $2 b$ & B \\
\hline $\begin{array}{l}\text { Flexible enteroscopy is the preferred primary appro- } \\
\text { ach in patients with active ongoing mid-gastrointesti- } \\
\text { nal bleeding with high probability of therapeutic } \\
\text { interventions }\end{array}$ & $2 b$ & B \\
\hline $\begin{array}{l}\text { Intraperative endoscopy should be reserved for } \\
\text { patients with persistent significant mid-gastrointesti- } \\
\text { nal bleeding in whom the bleeding source remains } \\
\text { undiagnosed by flexible enteroscopy }\end{array}$ & 5 & B \\
\hline $\begin{array}{l}\text { Flexible enteroscopy is the preferred primary ap- } \\
\text { proach for small-bowel evaluation in patients with } \\
\text { suspected stenoses or surgically modified anatomy } \\
{[23-26]}\end{array}$ & $2 b$ & B \\
\hline $\begin{array}{l}\text { The choice of either anal or oral route for the primary } \\
\text { procedure depends on the suspected location of } \\
\text { pathology within the small bowel (e.g. pathological } \\
\text { findings detected by capsule endoscopy or other } \\
\text { imaging modalities) [55] }\end{array}$ & $2 b$ & B \\
\hline $\begin{array}{l}\text { Endoscopic balloon dilation of small-bowel fibroste- } \\
\text { notic Crohn's strictures is a valuable therapeutic } \\
\text { option [24-26] }\end{array}$ & 4 & C \\
\hline $\begin{array}{l}\text { Resection of polyps within the small bowel can be } \\
\text { performed with a complication risk similar to that of } \\
\text { polyps in the right colon }[24,62-63]\end{array}$ & 4 & C \\
\hline $\begin{array}{l}\text { DBE allows endoscopic access to the biliary tree after } \\
\text { Billroth II or Roux-en-Y operation }[28-30]\end{array}$ & $2 b$ & B \\
\hline
\end{tabular}

DBE, double balloon enteroscopy; ESGE, European Society of Gastrointestinal Endoscopy.

\section{Double balloon enteroscopy}

The DBE system (Fujinon, Inc., Saitama, Japan) consists of a high-resolution video endoscope with a working length of $200 \mathrm{~cm}$ and a flexible overtube. Latex balloons are attached to the tip of the enteroscope and the overtube, and are inflated and deflated with air from a pressurecontrolled pump system. The principle of the DBE technique is based on alternating "push-andpull" maneuvers, with the inflated latex balloons anchoring the endoscope within the small bowel [1]. For small-bowel enteroscopy two different DBE enteroscopes are available. The EN-450P5 has a working channel of $2.2 \mathrm{~mm}$, an outer diameter of $8.5 \mathrm{~mm}$, and an overtube with an outer diameter of $12.2 \mathrm{~mm}$. The EN-450T5 has a working channel of $2.8 \mathrm{~mm}$, an outer diameter of $9.4 \mathrm{~mm}$, and an overtube diameter of $13.2 \mathrm{~mm}$.

\section{Single balloon enteroscopy}

Recently, a SBE system was proposed for small-bowel enteroscopy (Olympus, Tokyo Japan). The endoscope (XSIF-Q160Y) consists of a high-resolution enteroscope with a working length of $200 \mathrm{~cm}$. The device is equipped with a $2.8 \mathrm{~mm}$ accessory channel, and a transparent overtube with a latex-free balloon attached on its distal part. In contrast to the DBE device, there is no balloon attached at the enteroscope, and therefore stable position of the device has to be maintained by hooking the distal tip of the enteroscope into the small-bowel wall.

If deemed necessary, Fujinon DBE devices might also be used in a single balloon technique (if the balloon is not mounted at the tip of the enteroscope). As SBE is a very new technique there was only one peer-reviewed article [7] available at the time of writing. Therefore, if deemed ap- 
Table 2 Levels of evidence and grades of recommendation based on the Oxford Centre for Evidence Based Medicine (http://www.clbm.net/index.aspx?0 = 1025)

\begin{tabular}{|c|c|}
\hline Level & Individual study \\
\hline $1 \mathrm{a}$ & Systematic review with homogeneity level 1 diagnostic studies \\
\hline $1 \mathrm{~b}$ & Validating cohort study with good reference standards \\
\hline $1 \mathrm{c}$ & $\begin{array}{l}\text { Specificity is so high that a positive result rules in the diagnosis or sensitivity is so high that a } \\
\text { negative study rules out the diagnosis }\end{array}$ \\
\hline $2 \mathrm{a}$ & Systematic review with homogeneity of level $>2$ diagnostic studies \\
\hline $2 b$ & Exploratory cohort study with good reference standards \\
\hline $3 a$ & Systematic review with homogeneity of $3 \mathrm{~b}$ and better studies \\
\hline $3 b$ & Nonconsecutive study; or without consistently applied reference standards \\
\hline 4 & Case-control study, poor or nonindependent reference standard \\
\hline 5 & $\begin{array}{l}\text { Expert opinion without explicit critical appraisal, or based on physiology, bench research, or "first } \\
\text { principle" }\end{array}$ \\
\hline \multicolumn{2}{|c|}{ Grades of recommendation } \\
\hline A & Consistent level 1 studies \\
\hline B & Consistent level 2 or three studies or extrapolations from level 1 studies \\
\hline C & Level 4 studies or extrapolations from level 2 or 3 studies \\
\hline D & Level 5 evidence or troublingly inconsistent or inconclusive studies of any level \\
\hline
\end{tabular}

propriate, abstracts from the two major gastroenterology congresses (Digestive disease Week [DDW] and United European Gastroenterology Week [UEGW]) from 2007 are cited. These abstracts report the first preliminary results on the clinical utility of the system in small series $[8-11]$.

\section{Indications for small-bowel flexible enteroscopy}

In large series on push enteroscopy [5,12 - 14], DBE [1,15-22], and first reports on SBE [7 - 11], the main indications were suspected or known mid-gastrointestinal bleeding. Flexible endoscopy also proved useful for endoscopic diagnosis and histological confirmation of lesions detected by other imaging modalities [1,7-11,15-22], and can be considered the first diagnostic step in patients with suspected small-bowel stenosis [23] because capsule endoscopy should be avoided in these cases due to the risk of capsule retention. For nonsurgical interventions in the small bowel, flexible enteroscopy is the mainstay. As well as for hemostasis, flexible enteroscopy is indicated for polyp resections [24], balloon dilation of stenoses [24-26], preoperative marking of pathological findings (e.g. tattooing), and removal of foreign bodies [24,27] (e.g. retained capsule endoscope). Push enteroscopy is commonly used for the placement of percutaneous endoscopic jejunostomy if administration of alimentation directly into the small bowel is needed.

Whereas push enteroscopy is mainly reserved for small-bowel endoscopy, balloon-assisted endoscopy might also be applied for other indications. DBE provides safe endoscopic access to the surgically modified gastrointestinal tract, for example endoscopic retrograde cholangiopancreatography (ERCP) after Billroth II or Roux-en-Y operation [28-30], and access to the biliary tree or gastric remnant following bariatric surgery [31]. Moreover, there is a growing body of evidence that DBE and SBE might be useful for difficult colonoscopies [32-35].

\section{Contraindications for small-bowel flexible enteroscopy}

Contraindications for flexible enteroscopy are essentially similar to those for conventional upper gastrointestinal endoscopy and colonoscopy. Adhesions are no contraindication but are an obvious limitation to the procedure, as fixed small bowel limits the insertion depth and often causes considerable discomfort to the patient during and after the procedure.

\section{Role of flexible enteroscopy in rational small-bowel work-up}

\section{$\nabla$}

\section{Mid-gastrointestinal bleeding}

Small-bowel bleedings with an origin located between the papilla and the ileocecal valve are defined as mid-gastrointestinal bleeding [36]. The diagnostic yield of push enteroscopy was reported to be in the range of $20 \%-80 \%[12-14,37,38]$. However, many of the lesions detected with push enteroscopy might be in the range of a standard endoscope $[39,40]$. A recent metaanalysis showed that push enteroscopy is inferior to capsule endoscopy, with diagnostic yields

Important indications for smallbowel flexible enteroscopy are mid-gastrointestinal bleeding, diagnosis and histological confirmation of lesions, and endoscopic interventions within the small bowel. Balloon-assisted endoscopy might also be applied for ERCP in patients with surgically modified GI-tract, and for difficult colonoscopies. 
- For small-bowel bleedings the diagnostic yield of DBE is equivalent to that of capsule endoscopy. The yield of push enteroscopy is inferior to both of these techniques. The higher the probabiltiy of endoscopic intervention the more flexible enteroscopy should be considered as the first-line exploration. Although in these cases balloon-assisted enteroscopy might be considered as the first step, push enteroscopy is an easyto-apply alternative in cases of suspected bleeding in the proximal jejunum or if DBE/SBE is not readily available.
- Capsule endoscopy can be considered in patients without suspected stenosis and flexible enteroscopy might be performed if strictures cannot be ruled out. Direct visualization of the stenosis has an important impact on the choice of treatment (medical vs. endoscopic vs. surgical). of $28 \%$ and $65 \%$, respectively [41]. Push enteroscopy was also less effective than DBE in two prospective comparative trials [37,38]. In contrast the diagnostic yield of capsule endoscopy and DBE has been shown to be similar in several comparative studies [42-44]. There are no data reported yet showing how SBE compares to the other small-bowel endoscopic modalities. It is important to note that different yields of endoscopic modalities may not necessarily lead to differences in clinical outcome. As there are no randomized prospective studies on this issue yet, proposed algorithms for work-up of mid-gastrointestinal bleeding are based on feasibility and technical considerations ( $\bullet$ Fig. 1 ). In most patients with mid-gastrointestinal bleeding and a low probability of therapeutic intervention, capsule endoscopy can be considered the first diagnostic step. If indicated by the capsule findings, flexible enteroscopy should be applied as a follow-up procedure for targeted endoscopic treatment or for obtaining a histopathological diagnosis. In cases of a negative capsule endoscopy with overt ongoing mid-gastrointestinal bleeding, balloon-assisted enteroscopy should be considered. By contrast, flexible enteroscopy should be the first-line exploration in the following cases: a) in patients with active ongoing bleeding with a high probability of therapeutic interventions; b) in patients with surgically modified anatomy, especially those with an intestinal afferent loop (this cannot be assessed by capsule endoscopy) [31]; and c) in patients with suspected stenosis (clinically or by other imaging modalities). Although balloon-assisted enteroscopy might be considered the first step for most of these cases, push enteroscopy is an easy-to-apply alternative in cases of suspected bleeding in the proximal jejunum or if DBE/SBE is not readily available. There is good evidence for the impact of push enteroscopy on the management of patients with mid-gastrointestinal bleeding $[12-14,45,46]$. Concerning DBE, most published data show a high rate of endoscopic interventions ranging between $35 \%$ and $65 \%[1,15,18,20-22,24]$, but there are only preliminary data indicating that DBE-based hemostatic treatment has a positive effect on clinical outcome with significant reductions in recurrent mid-gastrointestinal bleeding and blood-transfusion requirements over a medium- to long-term follow-up period [21,47].

\section{Crohn's disease}

No single modality can be regarded as the gold standard for diagnosing or excluding small-bowel Crohn's disease. In suspected nonstricturing small-bowel Crohn's disease with normal findings at ileocolonoscopy (including normal histopathological findings) and other imaging modalities, capsule endoscopy should be the first diagnostic step; in cases of known or suspected Crohn's disease stricture, balloon-assisted enteroscopy is the method of choice to obtain endoscopic and histological confirmation [22]. In established Crohn's disease, for patients in whom small-bowel disease activity is suspected and significant findings have not been revealed by other modalities, capsule endoscopy can be considered in patients without suspected

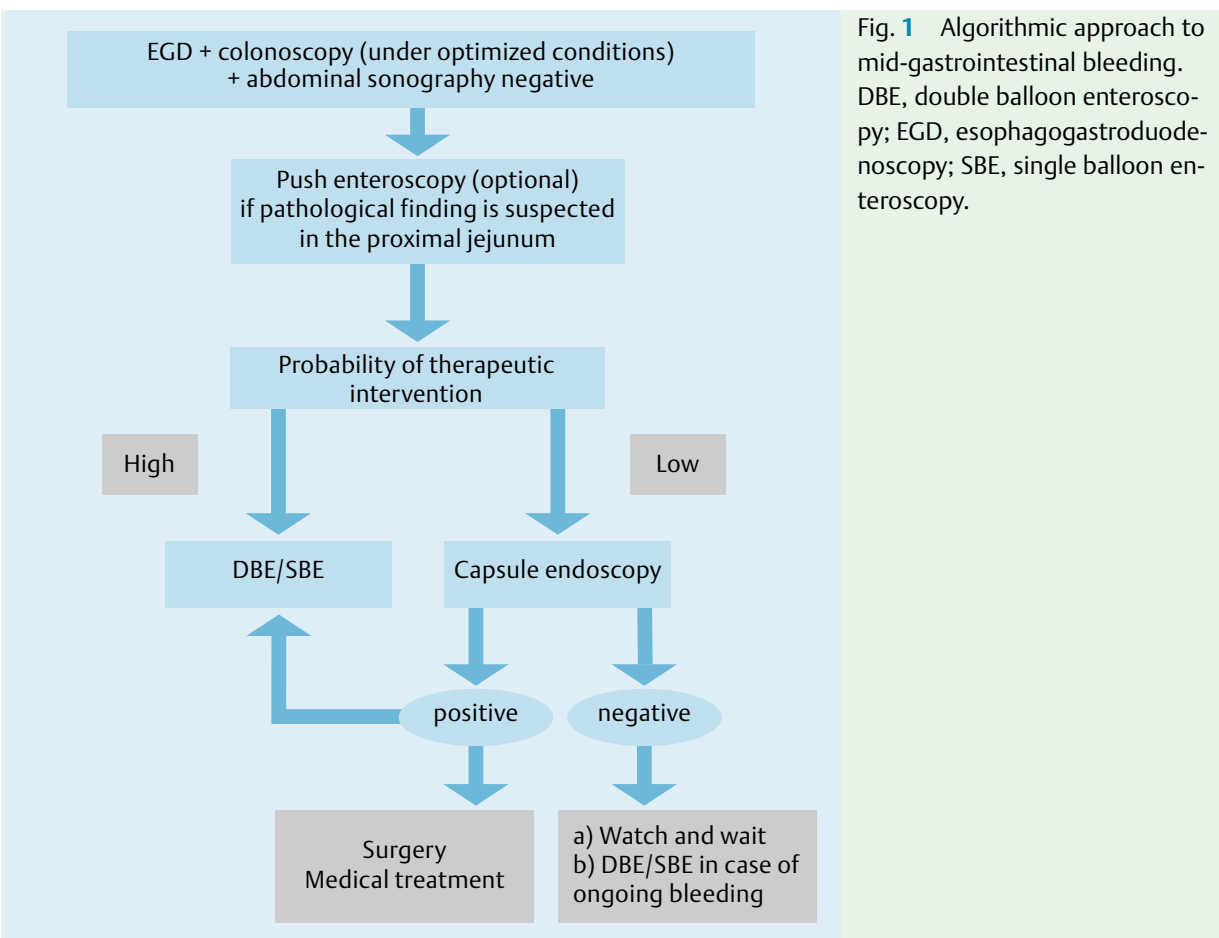


stenosis [48,49], and balloon-assisted enteroscopy might be performed if strictures cannot be ruled out. Flexible endoscopy is not only useful for diagnosis of obstructive Crohn's disease but is also essential for the choice of treatment. Direct visualization of the stenosis allows discrimination of patients with active inflammation within the stenotic bowel segment [10,24-26] who may benefit from medical treatment, and patients with tight fibrotic strictures that need immediate endoscopic or surgical treatment.

\section{Polyposis syndromes}

There is no evidence to support routine small-bowel work-up when a diagnosis of familial adenomatous polyposis is first made [50]. The role of capsule endoscopy in surveillance for patients with Spiegelman III and IV, who have increased frequency of jejunal and ileal polyps, needs to be determined. Subsequent flexible enteroscopy is only indicated if clinically relevant polyps are detected. Push enteroscopy is reserved for polyps located in the very proximal jejunum. In contrast, in patients with Peutz-Jeghers Syndrome capsule endoscopy should be routinely considered at the time of diagnosis for surveillance of small-bowel polyps. In patients with symptomatic Peutz-Jeghers Syndrome, particularly in those with obscure gastrointestinal bleeding in whom the diagnostic yield of significant polyps appears to be high, balloon-assisted enteroscopy should be considered as the first diagnostic modality.

\section{Small-bowel tumors}

The frequency of intestinal tumors in patients with obscure bleeding is reported to range between $5 \%$ and $10 \%[20,21]$. Up to $60 \%$ of the tumors are malignant [51]. A recently published consensus on capsule endoscopy stated that capsule endoscopy cannot distinguish benign from malignant lesions or even neoplastic from non-neoplastic ones [50]. Therefore, in patients with suspected small-bowel tumors (e.g. diagnosed by cross-sectional imaging techniques) balloon-assisted enteroscopy should be the first choice because of the ability to take biopsies of suspicious areas for histopathological diagnosis. For the same reason, in cases of refractory celiac disease [52] and for staging of gastrointestinal lymphoma beyond the stomach, balloonassisted enteroscopy should be the preferred first diagnostic step.

\section{Technical issues}

$\nabla$

\section{Preparation and handling of devices}

In most medical centers flexible enteroscopy of the small bowel constitutes a two-person procedure. Although compared with balloon-assisted enteroscopy push enteroscopy has the major disadvantages of limited insertion depth and restriction to the oral approach, there are three important benefits: a) there is no need to set up a special system (including a pump control system); b) the stiff push enteroscopy overtube is dispensable, therefore avoiding extra costs; and c) the procedure time is significantly shorter compared with balloon-assisted enteroscopy [38]. For DBE and SBE, the time required for setting up the systems appears to be similar.

\section{Intestinal preparation and prokinetics}

For balloon-assisted enteroscopy using the retrograde approach patients should have a full bowel preparation with some of the standard bowel preparations. For push enteroscopy and anterograde balloon enteroscopy a minimum of 10 hours fasting is warranted (small amounts of clear fluids are allowed until 4 hours before the procedure). There are insufficient data concerning the value of additional bowel preparation for anterograde balloon-assisted enteroscopy. However, in selected patients with known slow small-bowel transit time (e.g. patients with diabetes), bowel preparation is useful.

\section{Sedation}

In most cases of push enteroscopy and anterograde or retrograde balloon-assisted enteroscopy, conscious sedation is sufficient. For anterograde balloon-assisted enteroscopy deep monitored sedation (e.g. with propofol) or general anesthesia with intubation is widely accepted. For retrograde balloon-assisted enteroscopy, conscious sedation as for colonoscopy is sufficient in most cases. During withdrawal of the endoscope and during therapeutic interventions, spasmolytics might improve visualization of the small-bowel mucosa by reducing motility of the small bowel.
- Capsule endoscopy and/or other imaging modalities should be used for screening. If clinically relevant polyps are detected, balloon-assisted endoscopy should be the first therapeutic step if polypectomy is considered.

- In patients with suspected smallbowel tumors balloon-assisted enteroscopy should be the first choice because of the ability to take biopsies of suspicious areas for histopathological diagnosis. 
- Insufflation of $\mathrm{CO}_{2}$ is safe, reduces patient discomfort and might significantly improve intubation depth.
- Insertion depth of the endoscope into the small bowel is significantly better with balloon-assisted devices compared to push enteroscopy. DBE and SBE might achieve complete enteroscopy in selected patients by a combined anterograde and retrograde approach.

\section{Insufflation of gas}

As balloon enteroscopies are lengthy procedures, large volumes of air are usually insufflated leading to significant distension of the small bowel. Indeed, one of the main technical challenges of DBE is the formation of distended bowel loops and acute angulations with increasing amounts of gas intraluminally. Carbon dioxide $\left(\mathrm{CO}_{2}\right)$, unlike air, is rapidly absorbed from the bowel. Preliminary data indicate that bowel insufflation with $\mathrm{CO}_{2}$ instead of air enhances patient comfort and decreases the need for sedation [53]. Indeed, a recent randomized, doubleblind trial showed that insufflation with $\mathrm{CO}_{2}$ is safe, reduces patient discomfort, and significantly improves intubation depth [54]. However, these results need to be confirmed by other studies before $\mathrm{CO}_{2}$ can be recommended as the standard insufflation gas in balloon enteroscopy.

\section{Determination of the primary insertion route}

The choice of either anal or oral route for the primary procedure depends on the suspected location of pathology within the small bowel. In cases in which balloon-assisted enteroscopy is performed secondary to pathological findings at capsule endoscopy, capsule endoscopy can obviously indicate the route for balloon-assisted enteroscopy, thus avoiding double procedures [55]. The locations of findings are assessed from the time axis of the capsule endoscopy recording between the pylorus and cecal entry (location in the upper two-thirds according to the capsule endoscopy recording indicates balloon-assisted enteroscopy via the oral route, in the lower third via the anal approach [55]).

\section{Procedural issues \\ $\nabla$}

Performance of small-bowel flexible enteroscopy modalities: insertion depth and procedure times

The small intestine in human adults is over $5 \mathrm{~m}$ in length [56]. Due to the absence of true landmarks in the small bowel, insertion depth is difficult to assess. At DBE the insertion depth of the endoscope into the small bowel can be estimated by recording the "net" advancement of the endoscope for each push and pull maneuver on a standardized documentation sheet [57]. For SBE this might not be feasible, because the angulated tip of the endoscope during the pull maneuver obstructs the view.

Push enteroscopy can definitely not evaluate the nonoperated small bowel in its entire length, and reported mean postpyloric insertion depth from the oral route range between $40 \mathrm{~cm}$ and $120 \mathrm{~cm}[37,38,58]$. Although with DBE, total enteroscopy via the anterograde approach alone can be performed in $\sim 5 \%$ of patients, complete enteroscopy by a combination of the anterograde or retrograde approaches may be achieved in $40 \%-80 \%$ of cases $[16,18,20,22]$. Preliminary reports suggest that complete enteroscopy with the combined approach might also be achieved with SBE [7,10-11]. Ongoing randomized trials are investigating whether rates of complete enteroscopy with SBE are comparable to those of DBE. Regardless of the balloon-assisted device used, when the combination of anterograde or retrograde procedures is planned, it is recommended that a tattoo and/or marking-clip is placed at the deepest point of insertion as a mark to assist in confirming total enteroscopy during the subsequent procedure from the opposite direction. Unless an emergency dictates otherwise, the procedure from the opposite direction should ideally be performed one or a few days later because of concerns about residual air in the intestinal lumen.

Concerning the procedure time, comparative studies have shown that the mean examination time for push enteroscopy is significantly shorter, requiring approximately half the time of DBE procedures $[37,38]$. In preliminary results exploration times for anterograde and retrograde SBE appear to be similar to DBE [7-11].

\section{Fluoroscopic control in small-bowel flexible enteroscopy}

Although published data concerning the real impact of fluoroscopy are not yet available, fluoroscopy appears to be used by most endoscopists for flexible enteroscopy when no further progress can be made. For DBE, less fluoroscopy is used with increasing experience [19], and some centers report application of fluoroscopy in less than $10 \%$ of DBE procedures. For some patients with surgically modified anatomy and for those undergoing therapeutic procedures such as ERCP or dilations, flexible enteroscopy usually requires fluoroscopic guidance. 


\section{Endoscopic treatment: options and limits}

$\nabla$

Due to the length of the endoscopes and loop formation within the small bowel, advancement of devices through the working channel might be troublesome. In these cases, straightening of the endoscope and lubrication of the working channel (e.g. with silicon oil), is recommended to facilitate insertion of devices through the working channel.

\section{Endoscopic resections within the small bowel}

Although endoscopic resections in the proximal small bowel can be performed by push enteroscopy and balloon-assisted enteroscopy, balloon-assisted devices may achieve a more stable position due to balloon anchoring of the overtube in a dedicated distance from the lesion. Prior to endoscopic resection in the small bowel, submucosal injection may be helpful [24]. The majority of endoscopists use a diluted epinephrine-saline solution. However, no data exist on the real value of injection prior to endoscopic resection in the small bowel. For large polyps with a broad base or thick stalk, piecemeal resection is in general recommended to lower the complication risk.

\section{Exploration and balloon dilation of small-bowel strictures}

Balloon-assisted enteroscopy offers not only endoscopic and histopathological diagnosis but also exploration and endoscopic treatment of small-bowel strictures. Characterization of the anatomy of the stricture can be obtained easily with a selective enteroclysis. Fistulas, not uncommon near Crohn's disease stenoses, can be excluded. Short-segment fibrostenotic Crohn's disease strictures without significant angulation or inflammation are amenable to endoscopic balloon dilation with push enteroscopy, DBE [24-27], and SBE [10]. Endoscopic devices with an accessory channel of $2.8 \mathrm{~mm}$ allow placement of a standard balloon dilator through the scope for dilation under endoscopic control.

In contrast, balloon dilation with devices with smaller accessory channels is performed under fluoroscopic guidance over a wire through the overtube after removal of the enteroscope. Although both procedures appear to be safe and effective for strictures, the outcome should be evaluated in large prospective multicenter trials.

\section{Hemostatic treatment}

Most sources of small-bowel bleeding are sufficiently treated by argon plasma coagulation or injection of saline/epinephrine solution [24]. Devices for argon plasma coagulation and injection can be introduced easily through the working channel of all available push enteroscopy, SBE, and DBE devices. Metal clip devices can be introduced through endoscopes with working channels of at least $2.8 \mathrm{~mm}$. However, clipping of bleeding small-bowel lesions should be reserved for selected cases with Forrest Ia bleeding or bleedings that cannot be otherwise managed.

\section{Complications}

Push enteroscopy is a safe procedure and serious complications are reported in less than $1 \%$ of procedures [43-46,58]. However, particularly with the use of a stiff overtube, mucosal stripping [59], duodenal perforation [60], pancreatitis and Mallory-Weiss tear [61] have been reported. For DBE, large surveys have shown that the complication rate of diagnostic procedures is low $(0.4 \%-0.8 \%)[62,63]$. In diagnostic procedures via the anterograde approach, pancreatitis is the most severe complication [62,64]. The overall complication rate of therapeutic DBE is about 3\%-4\% (perforation, bleeding). However difficult therapeutic endoscopic procedures (e.g. resection of large polyps) may increase the risk to $10 \%[62,63]$. Concerning SBE, in the first small series [7 - 11], no serious complications were reported. However, further large studies are required to determine whether the pull maneuver with angulated tip of the endoscope without an inflated protecting balloon is a safe procedure.
- Endoscopic balloon dilation appears to be a safe and effective procedure in short-segment fibrostenotic strictures.

- For treatment of small-bowel bleeding APC or injection of saline/epinephrine solution are considered first choice.

- Complication rates for diagnostic and therapeutic push enteroscopy and DBE are $<1 \%$ and $3 \%-4 \%$, respectively. For SBE, complication rates remain to be determined by further large studies. 


\section{Conclusions \\ $\nabla$}

Endoscopic examination of the small bowel has dramatically improved with the advent of capsule enteroscopy and later by balloon-assisted enteroscopy. Both techniques are now available in clinical practice and fruitfully complement each other. DBE enables endoscopists to perform the same therapeutic procedures as in gastroscopy or colonoscopy. It remains to be determined whether SBE provides diagnostic and therapeutic efficacy comparable to DBE. It is likely that the indications for DBE procedures will expand further in the future, and that novel uses of the balloon-assisted techniques will be established. Finally, clinical outcome studies as well as cost-effectiveness analyses for the diverse indications are needed.

\section{European Society of Gastrointestinal Endoscopy (ESGE) Clinical Guidelines Committee Co-Chairmen: Spiros D. Ladas (Greece), Rainer Schoefl (Austria)}

Members: Simon Bar Meir (Israel), Miguel Munoz-Navas (Spain), Thierry Ponchon (France).

\section{Competing interests: None}

\section{Institutions}

${ }^{1}$ Department of Internal Medicine II, Dr Horst Schmidt Kliniken, Wiesbaden, Germany

${ }^{2}$ CHU de Nancy, Vandoeuvre les Nancy, France

${ }^{3}$ Department of Gastroenterology, VU Medisch Centrum, Amsterdam, The Netherlands

${ }^{4}$ Division of Gastroenterology 2, San Giovanni A.S. Hospital, Turin, Italy

5 Small Bowel Unit, Hospital Morales Meseguer, Murcia, Spain

${ }^{6}$ Gentofte University Hospital, Hellerup, Denmark

\section{References}

1 Yamamoto H, Sekine Y, Sato Y et al. Total enteroscopy with a non surgical steerable double-balloon method. Gastrointest Endosc 2001; 53: 216-220

2 Taylor AC, Chen RY, Desmond PV. Use of an overtube for enteroscopy - does it increase depth of insertion? A prospective study of enteroscopy with and without an overtube. Endoscopy 2001; 33: 227 - 230

3 lida M, Yamamoto T, Yao T et al. Jejunal endoscopy using a long duodenofiberscope. Gastrointest Endosc 1986; 32: $233-236$

4 Keizman D, Brill S, Umansky $M$ et al. Diagnostic yield of routine push enteroscopy with a graded-stiffness enteroscope without overtube. Gastrointest Endosc 2003; 57: 877 - 881

5 Lin S, Branch MS, Shetzline M. The importance of indication in the diagnostic value of push enteroscopy. Endoscopy 2003; 35: 315-321

6 Belaiche J, van Kemseke C, Louis E. Use of enteroscope for colo-ileoscopy: low yield in unexplained lower gastrointestinal bleeding. Endoscopy 1999; 31: 298-301

7 Tsujikawa T, Saitoh Y, Andoh A et al. Novel single-balloon enteroscopy for diagnosis and treatment of the small intestine: preliminary experiences. Endoscopy 2008; 40: 11 - 15

8 Lapalus M, Ponchon T, Chemali $M$ et al. Single-balloon enteroscopy: a preliminary experience. Gastrointest Endosc 2007; 65: AB184

9 Vargo JJ, Upchruch B, Dumot JA et al. Clinical utility of the olympus single balloon enteroscope: the initial U.S. experience. Gastrointest Endosc 2007; 65: AB90

10 Nakahara T, Tsujikawa T, Imaeda $\mathrm{H}$ et al. Efficacy of novel single balloon enteroscope for the small intestine. Endoscopy 2007; 39 (Suppl I): A382

11 Ohtsuka K, Kashida H, Kodama K et al. Diagnosis and treatment of small intestinal diseases using newly developed single balloon endoscope. Endoscopy 2007; 39 (Suppl I): A383

12 Chak A, Koehler MK, Sundaram SN et al. Diagnostic and therapeutic impact of push enteroscopy: analysis of factors associated with positive findings. Gastrointest Endosc 1998; 47: 18-22

13 Davies GR, Benson MJ, Gertner DJ et al. Diagnostic and therapeutic push type enteroscopy in clinical use. Gut 1995; 37: $346-352$

14 Taylor AC, Buttigieg RJ, McDonald IG et al. Prospective assessment of the diagnostic and therapeutic impact of small-bowel push enteroscopy. Endoscopy 2003; 35: 951 - 956

15 Ell C, May A, Nachbar L et al. Push-and-pull enteroscopy in the small bowel using the double-balloon technique: results of a prospective European multicenter study. Endoscopy 2005; 37: 613-616

16 Sun B, Rajan E, Cheng $S$ et al. Diagnostic yield and therapeutic impact of double-balloon enteroscopy in a large cohort of patients with obscure gastrointestinal bleeding. Am J Gastroenterol 2006; 101: $2011-2115$

17 Kita H, Yamamoto $\mathrm{H}$, Yano $\mathrm{T}$ et al. Double balloon endoscopy in two hundred fifty cases for the diagnosis and treatment of small intestinal disorders. Inflammopharmacology 2007; 15: 74-77

18 May A, Nachbar L, Ell C. Double-balloon enteroscopy (push-and-pull-enteroscopy) of the small bowel: feasibility and diagnostic and therapeutic yield in patients with suspected small bowel disease. Gastrointest Endosc 2005; 62: $62-70$

19 Mehdizadeh S, Ross A, Gerson L et al. What is the learning curve associated with double-balloon enteroscopy? Technical details and early experience in 6 U.S. tertiary care centers. Gastrointest Endosc 2006; 64: 740 - 750

20 Heine G, Hadithi M, Groenen M et al. Double balloon enteroscopy: Indications, diagnostic yield, and complications in a series of 275 patients with suspected small-bowel-diseases. Endoscopy 2006; 38: $42-48$

21 Zhong J, Ma T, Zhang C et al. : A retrospective study of the application on double-balloon enteroscopy in 378 patients with suspected small-bowel diseases. Endoscopy 2007; 39: 208- 215

22 Yamamoto $\mathrm{H}$, Kita H, Sunada K et al. Clinical outcomes of double-balloon endoscopy for the diagnosis and treatment of small-intestinal diseases. Clin Gastroenterol Hepatol 2004; 2: 1010-1016 
23 Sunada K, Yamamoto $\mathrm{H}$, Kita $\mathrm{H}$ et al. Clinical outcomes of enteroscopy using the double-balloon method for strictures of the small intestine. World J Gastroenterol 2005; 11: 1087-1089

24 May A, Nachbar L, Pohl J et al. Endoscopic interventions in the small bowel using double-balloon enteroscopy: feasibility and limitations. Am J Gastroenterol 2007; 102: 527- 535

25 Pohl J, May A, Nachbar L et al. Diagnostic and therapeutic yield of push-and-pull enteroscopy for symptomatic small bowel Crohn's strictures. Eur J Gastroenterol Hepatol 2007; 19: 529-534

26 Fukumoto A, Tanaka S, Yamamoto $\mathrm{H}$ et al. Diagnosis and treatment of small-bowel strictures by double balloon endoscopy. Gastrointest Endosc 2007; 66: 108-112

27 Lee BI, Choi H, Choi KY et al. Retrieval of a retained capsule endoscope by double-balloon enteroscopy. Gastrointest Endosc 2005; 62: 463-465

28 Haruta $\mathrm{H}$, Yamamoto $\mathrm{H}$, Mizuta $\mathrm{K}$ et al. A case of successfull enteroscopic balloon dilation for late anastomotic stricture of choledochojejunostomy after living donor liver transplantation. Liver Transpl 2005; 11: 1608 - 1610

29 Kuno A, Yamamoto H, Kita H et al. Double-balloon enteroscopy through a Roux-en-Y anastomosis for EMR of an early carcinoma in the afferent duodenal limb. Gastrointest Endosc 2004; 60: 1032 - 1034

30 Aabakken L, Bretthauer M, Line PD. Double-balloon enteroscopy for endoscopic retrograde cholangiography in patients with a Roux-en-Y anastomosis. Endoscopy 2007; 39: 1068 - 1071

31 Sakai P, Kuga R, Safatle-Ribeiro AV et al. Is it feasible to reach the by-passed stomach after Roux-en-Y-gastric by pass for morbid obesity? The use of the double-balloon enteroscope. Endoscopy 2005; 37: 566- 569

32 May A, Nachbar L, Ell C. Push-and-Pull Enteroscopy using a single-balloon technique for difficult colonoscopy. Endoscopy 2006; 38: 395-398

33 Monkemueller K, Knippig C, Rickes S et al. Usefulness of the DBE in colonoscopies performed in patients with previously failed colonoscopy. Scand J Gastroenterol 2007; 30: 277- 278

34 Kaltenbach $T$, Soetikno R, Friedland S. Use of a double balloon enteroscope facilitates caecal intubation after incomplete colonoscopy with a standard colonoscope. Dig Liver Dis 2006; 38: 921 - 925

35 Pasha SF, Harrison ME, Das A et al. Utility of double-balloon colonoscopy for completion of colon examination after incomplete colonoscopy with conventional colonoscope. Gastrointest Endosc 2007; 65: 848 - 853

36 Ell C, May A. Mid-gastrointestinal bleeding: capsule endoscopy and push-and-pull enteroscopy give rise to a new medical term. Endoscopy 2006; 38: 73-75

37 May A, Nachbar L, Schneider $M$ et al. Prospective comparison of push enteroscopy and push-and-pull enteroscopy in patients with suspected small-bowel bleeding. Am J Gastroenterol 2006; 100: 12016-12024

38 Matsumoto T, Moriyama T, Esaki $M$ et al. Performance of antegrade double-balloon enteroscopy: comparison with push enteroscopy. Gastrointest Endosc 2006; 62: 392 - 398

39 Zaman A, Katon RM. Push enteroscopy for obscure gastrointestinal bleeding yields a high incidence of proximal lesions within reach of a standard endoscope. Gastrointest Endosc 1998; 47: 372 - 376

40 Lara LF, Bloomfeld RS, Pineau BC. The rate of lesions found within reach of esophagogastroduodenoscopy during push enteroscopy depends on the type of obscure gastrointestinal bleeding. Endoscopy 2005; 37: 745-750

41 Triester SL, Leighton JA, Leontiadis GI et al. A meta-analysis of the yield of capsule endoscopy compared to other diagnostic modalities in patients with obscure Gl bleeding. Am J Gastroenterol 2005; 100: 2407-2418

42 Matsumoto T, Esaki M, Moriyama T et al. Comparison of capsule endoscopy and enteroscopy with the doubleballoon method in patients with obscure bleeding and polyposis. Endoscopy 2005; 37: 827-832

43 Nakamura M, Niwa Y, Ohmiya N et al. Preliminary comparison of capsule endoscopy and double-balloon enteroscopy in patients with suspected small-bowel bleeding. Endoscopy 2006; 38: 59-66

44 Hadithi M, Heine GD, Jacobs MA et al. A prospective study comparing video capsule endoscopy with double-balloon enteroscopy in patients with obscure gastrointestinal bleeding. Gastroenterology 2006; 131: 327 - 329

45 Hayat M, Axon AT, O'Mahony S. Diagnostic yield and effect on clinical outcomes of push enteroscopy in suspected small bowel bleeding. Endoscopy 2000; 32: 369-372

46 Nguyen NQ, Rayner CK, Schoeman MN. Push enteroscopy alters management in a majority of patients with obscure gastrointestinal bleeding. I Gastroenterol Hepatol 2005; 20: 716 - 721

$47 \mathrm{Kaffes} \mathrm{AJ,} \mathrm{Siah} \mathrm{C,} \mathrm{Koo} \mathrm{JH.} \mathrm{Clinical} \mathrm{outcomes} \mathrm{after} \mathrm{double-balloon} \mathrm{enteroscopy} \mathrm{in} \mathrm{patients} \mathrm{with} \mathrm{obscure} \mathrm{GI} \mathrm{blee-}$ ding and a positive capsule endoscopy. Gastrointest Endosc 2007; 66: 304 - 309

48 Voderholzer WA. The role of PillCam endoscopy in Crohn"s disease: the European experience. Gastrointest Endosc Clin N Am 2006; 16: 287 - 297

49 Triester SL, Leighton JA, Leontiadis GI et al. A meta-analysis of the yield of capsule endoscopy compared to other diagnostic modalities in patients with non-stricturing small bowel Crohn"s disease. Am J Gastroenterol 2006; 101: $954-964$

50 Mergener K, Ponchon T, Gralnek I et al. Literature review and recommendations for clinical application of smallbowel capsule endoscopy, based on a panel discussion by international experts. Consensus statement for smallbowel capsule endoscopy, 2006/2007. Endoscopy 2007; 39: 895-909

51 Schwarzt GD, Barkin JS. Small-bowel tumors detected by wireless capsule endoscopy. Dig Dis Sci 2007; 52: $1026-1030$

52 Hadithi M, Al-Toma A, Oudejans J et al. The value of double-balloon enteroscopy in patients with refractory celiac disease. Am J Gastroenterol 2007; 102: 987-996

53 Hirai F, Matsui T, Yao K et al. Efficacy of carbon dioxide insufflation in endoscopic balloon dilation therapy using double balloon endoscopy. Gastrointest Endosc 2007; 66: $26-29$

54 Domagk D, Bretthauer M, Lenz $P$ et al. Carbon dioxide insufflation improves intubation depth in double-balloon enteroscopy: a randomized, controlled, double-blind trial. Endoscopy 2007; 39: 1064- 1067

55 Gay G, Delvaux M, Fassler I. Outcome of capsule endoscopy in determining indication and route for push-andpull-enteroscopy. Endoscopy 2006; 38: 49-58

56 Weaver LT, Austin S, Cole TJ. Small intestinal length: a factor essential for gut adaption. Gut 1991; 32: 1321 - 1323

57 May A, Nachbar L, Schneider M et al. Push-and-pull enteroscopy using the double-balloon technique: method of assessing depth of insertion and training of the enteroscopy technique using the Erlangen Endo-Trainer. Endoscopy 2005; 37: $66-70$

58 De Leusse A, Vahedi K, Edery J et al. Capsule endoscopy or push enteroscopy for first-line exploration of obscure gastrointestinal bleeding. Gastroenterology 2007; 132: 855-862

59 Yang R, Laine L. Mucosal stripping: a complication of push enteroscopy. Gastrointest Endosc 1995; 41: 156-158 
60 Landi B, Tkoub M, Gaudric M et al. Diagnostic yield of push-type enteroscopy in relation to indication. Gut 1998; 42: $421-425$

61 Barkin JS, Lewis BS, Reiner DK et al. Diagnostic and therapeutic jejunostomy with a new, longer enteroscope. Gastrointest Endosc 1992; 38: 55- 58

62 Mensink P, Haringsma J, Kucharzik TF et al. Complications of double balloon enteroscopy: a multicenter survey. Endoscopy 2007; 39: 613-615

63 Moeschler O, May A, Mueller MK et al. Complications and more: Results of the German Prospective DBE-Database by the German DBE Study Group. Gastrointest Endosc 2008; 67: AB262

64 Groenen MJM, Moreels TGG, Orlent $H$ et al. Acute pancreatitis after double-balloon enteroscopy: an old pathogenetic theory revisited as a result of using a new endoscopic tool. Endoscopy 2006; 38: 82 - 85 